\title{
Monitoring of Drought Awareness from Google Trends: A Case Study of the 2011-17 California Drought $\mathscr{0}$
}

\author{
JONGHUN KAM \\ Department of Civil, Construction, and Environmental Engineering, University of Alabama, and Alabama Water \\ Institute, and Center for Complex Hydrosystems Research, Tuscaloosa, Alabama \\ KIMBERLY STOWERS \\ Department of Management, University of Alabama, Tuscaloosa, Alabama

\section{SUNGYOON KIM} \\ Department of Civil, Construction, and Environmental Engineering, University of Alabama, Tuscaloosa, Alabama
}

(Manuscript received 8 August 2018, in final form 4 February 2019)

\begin{abstract}
This study introduces "Google Trends" as a social data source in monitoring and modeling the dynamics of drought awareness during the 2011-17 California drought. In this study, drought awareness is defined and operationalized as the relative search interest activities within California, using the search term "drought" from Google Trends. First, the 2011-17 California drought is characterized in the duration-intensity curve with other historical California droughts for comparative purposes, using the 12-month standard precipitation index data (1895-2017). Second, the potential triggers of the peaks of drought awareness during the 2011-17 California drought are investigated through Google Trends and Google Search. The Google Trends data show that the first peak of drought awareness occurred when the drought condition reached its peak and the governor declared the drought emergency (January 2014). The other peaks in August 2014, April 2015, and January 2017 are related to public interest in drought recovery driven by the forecast of the strong El Niño winter of 2014/15, the governor's issue of water use rules, and California floods in early 2017, respectively. Last, a power-law decay model of drought awareness is fitted to the Google Trends data. According to the fitted power-law model, Californians remained interested in drought after the social trigger-related peaks longer than they did after the natural trigger-related peaks. The findings of this study suggest that it is necessary to develop a more realistic social dynamic modeling for communities that can respond to natural and human triggers and capture interactions with awareness of related disasters.
\end{abstract}

\section{Introduction}

Drought is an extreme event that naturally occurs in the climate system. Severe droughts have adverse effects in the entire ecological community. Recently, California (CA) experienced an exceptional drought (2011-17) causing severe economic and ecological losses-including \$5.5 billion in agricultural losses from 2014 through 2016 (Howitt et al. 2014, 2015; Medellín-Azuara et al. 2016)

Supplemental information related to this paper is available at the Journals Online website: https://doi.org/10.1175/WCAS-D-180085.s1.

Corresponding author: Dr. Jonghun Kam, jkam@eng.ua.edu and about 130 million dead trees (Buluç et al. 2017). The drought research community has made rigorous efforts to understand the origins, mechanisms, and predictability of the 2011-17 CA drought; these efforts ultimately contributed to a significant advancement of our understanding. For example, Geophysical Research Letters has a special collection titled "The ongoing California Drought of 2012-2015: A testbed for understanding regional climate extremes in a warming world" including 24 publications related at the time of writing (14 January 2019).

Despite the enhanced understanding of the generating mechanisms, less work has been completed on the social dynamics of drought and their impacts on drought management and public policy. Case studies have suggested 
that both awareness and risk perception of drought may impact management of and response to drought. For example, a case study of CA responses to water scarcity showed that the state's current strategies for dealing with long or severe droughts may not be as successful as previously believed (Christian-Smith et al. 2015). Furthermore, when considering broader-scale events such as climate change as a whole, a study of farmers in CA suggested that understanding responses to environmental risks and hazards may show why citizens may not respond appropriately to events (Niles et al. 2013).

Understanding the dynamics of social response to the evolution of natural disasters is challenging because of the lack of coupled dynamic modeling and social monitoring data. In recent years, the hydrologic modeling community proposed a new multidisciplinary branch, "socio-hydrology" (Sivapalan et al. 2012), to capture the coupled dynamics of natural and human systems. The dominant approach in sociohydrology has been focused on conceptualizing and modeling the coupled dynamics of human-natural systems for hypothetical communities (Di Baldassarre et al. 2013; van Emmerik et al. 2014; Sivapalan et al. 2012). It also introduced new concepts of decision-making processes (Aerts et al. 2018; Viglione et al. 2014; Yu et al. 2017) into the sociohydrologic modeling framework. A recent study (Di Baldassarre et al. 2017) attempted to model the coupled human-natural systems, particularly the dynamic of flood and drought memory in the dam operation system. However, understanding the triggers and dynamics of drought awareness is more challenging because drought is a creeping phenomenon that slowly grows and occurs across different temporal scales, resulting in a broad impact on many sectors of the economy. As such, when pursuing sociohydrologic modeling of drought awareness, it is a prerequisite to understand the potential triggers of the peaks of drought awareness during the emergence of drought and the decay patterns of drought awareness after the peaks. The proposed sociohydrologic modeling has the power to describe social response during the emergence of disasters from possible simulations of hypothetical communities.

Despite the rapid growth of sociohydrologic modeling in recent years, there are some debates and suggestions for future research directions on sociohydrology. Missing social data for model validation and evaluation is a major concern of sociohydrologic modeling (Troy et al. 2015). Increased participation from social scientists is also encouraged to make sociohydrology a more synthetic theme to include hazards, sustainability, resilience, and adaptive governance (Xu et al. 2018). Qualitative assessment was proposed through a case study as an alternative approach for sociohydrology (Mostert 2018), which can allow hydrologists and sociologists to better understand the social response in a specific social structure to a specific disaster through in-depth data collection from multiple sources.

Mass media coverage has been identified as a key factor that can impact public awareness of natural events and possibly drought. For example, mass media coverage has been shown to have an impact on public awareness of climate-change issues (Sampei and Aoyagi-Usui 2009) and even water consumption (Quesnel and Ajami 2017). Prior research on public awareness of natural hazards has shown that the Internet is also a powerful tool for managing public awareness. For example, the National Oceanic and Atmospheric Administration has created an online directory providing citizens access to data an information relating to natural hazards (Dunbar 2007). However, providing information via government websites is limited by the fact that many citizens may not easily find their way to these sites. Instead, the use of social media may be more helpful for increasing public awareness through social networks. Research examining the use of social media platforms during the recent CA drought showed that government agencies used social media sites such as Facebook, YouTube, and Twitter to communicate with the public about the drought, but that communication tended to be superficial, with gaps between public and personal social media conversations (Tang et al. 2015). Thus, additional research is needed to understand how citizens may have explored information about drought in more private ways, for example through searching for information via Google, to form their opinion during the stages of drought onset, persistence, and recovery.

Traditional data collection from surveys about drought awareness is limited in conveying the social dynamics of drought emergence due to the time-consuming data collection process and limited size of data samples. A recent study (Switzer and Vedlitz 2017) examined data from two nationally representative probability-based panel surveys, and found that individual awareness of drought drives concern for water shortages and ultimately support for water policy. This study indicates that understanding the potential triggers of the peaks of drought awareness is crucial for developing proactive strategies for drought adaptation and response. The findings of this study are, however, based on a static logistic regression model of the panel survey responses. Further, the authors operationalize local drought awareness as the correctness of participant responses to the question "When did you last experience a drought or water shortage in your community?" Survey questions 
are focused on individual awareness during the peak of drought and do not capture their awareness during the onset or recovery of drought. This highlights multiple challenges in the examination of historical drought events using social science. First, post hoc data collection methods that rely on survey responses or interviews often fail to capture the longitudinal, evolving perceptions of citizens that experience these events. Additionally, due to the nature of human memory, which reconstructs past events rather than recalling them as snapshots of what happened, citizens' own accounts of historic events-even if such events are significantmay not be accurate (Bartlett 1932; Neisser and Harsch 1992). To that end, what are other potential data sources for social monitoring and how can we collect social data with large enough temporal coverage and accuracy to address these challenges?

Over the last decade, social monitoring data through web-search and social media activities have been discovered as ground-breaking data sources for social science and public health because of the unprecedented sample sizes at high spatial and temporal resolutions, resulting in a near-real-time monitoring system (Choi and Varian 2012; Seifter et al. 2010; Vosen and Schmidt 2011). Social data from web searches and social media provide a new opportunity to develop and monitor social indicators, in particular for developed countries. Their statistical reliability should be further studied because of noise from irrelevant social events or topics to the search/interest term (Murdock 2011). However, few studies attempt to understand and model drought awareness using web searches and social media data. A recent study (Gonzales and Ajami 2017) tested the "rebounding" water use theory during the 2011-17 CA drought through a dynamic social memory model and validated their model performance against the time series of search interest during the 2011-17 CA drought from Google Trends data. Another recent preliminary study (Musaev et al. 2018) used retweet activities from Twitter to explore its possible determinants of drought awareness during the 2011-17 CA drought. As insightful as these studies were, neither of them investigated how drought awareness can be modeled using the web-search and social media data to capture social response of real communities to drought.

Here, we investigate how drought awareness changes during the 2011-17 CA drought using Google Trends data. In this study, drought awareness is defined and operationalized as the relative search interest activities from Google Trends. This study attempts to answer the following questions: 1) How severe is the 2011-17 CA drought in terms of duration and intensity in comparison with other identified CA droughts? 2) What are the potential triggers (natural and/or societal) of the peaks of drought awareness during the 2011-17 CA drought? 3) Are Google Trends data a reliable data source to model and characterize social response to drought? By answering these questions, we can gain a better understanding of the triggers and dynamics of drought awareness, as well as new insight into the use of Google Trends to improve sociohydrological modeling for capturing the dynamics of drought awareness.

In the next section, the data and methods used in this study are described. The results section includes findings from an analysis of the characteristics of the historical CA droughts-including the 2011-17 drought using the duration-intensity (D-I) curve-as well as an analysis of social dynamics along the propagations of the 2011-17 CA drought from Google Trends and Google Search data. Also, we describe and characterize the decay patterns of drought awareness after the four peaks during the 2011-17 CA drought based on the estimated parameters of the fitted power-law decay model to the Google Trends data. In closing, we summarize the findings of this study and discuss potential applications of Google Trends to the development of proactive drought preparation and mitigation plans within the sociohydrological modeling framework.

\section{Data and methods}

\section{a. Precipitation and standard precipitation indices}

This study focuses on the characteristics of meteorological CA droughts. We compute the regional averages of monthly precipitation over CA using the gridded mask of the state of CA (Fig. 1a) and monthly precipitation data from the PRISM at 4-km spatial resolution (1895-2017; Daly et al. 2008). We find no significant trend of monthly precipitation anomalies over CA over 1895-2017 from the nonparametric Mann-Kendall test (Sen 1968) (Fig. 1b). We compute monthly precipitation anomalies by subtracting the long-term average (1895-2017) from monthly precipitation. Also, we compute the 3- and 12-month standard precipitation index (SPI3 and SPI12; McKee et al. 1993) from the monthly time series of the regional averages using an NCL function ("dim_spi_n"). Here, the SPI3 is used to detect the pluvial events over CA (Fig. 2a). The SPI12 is used to detect the onset, persistence, and recovery of drought and to quantify the duration and intensity (the peak of drought severity) (Fig. 2b). The SPI3 and SPI12 are often used as a good indicator of short-term and long-term droughts, respectively, since they depict the accumulative deficit/surplus over the past 3 and 12 months. 
(a)

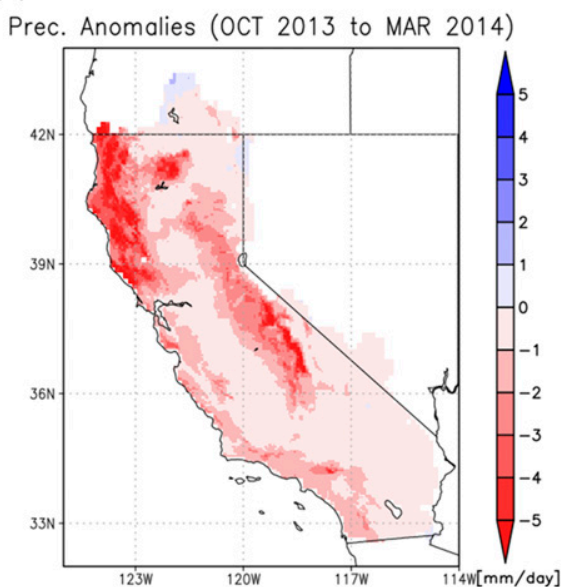

(b)

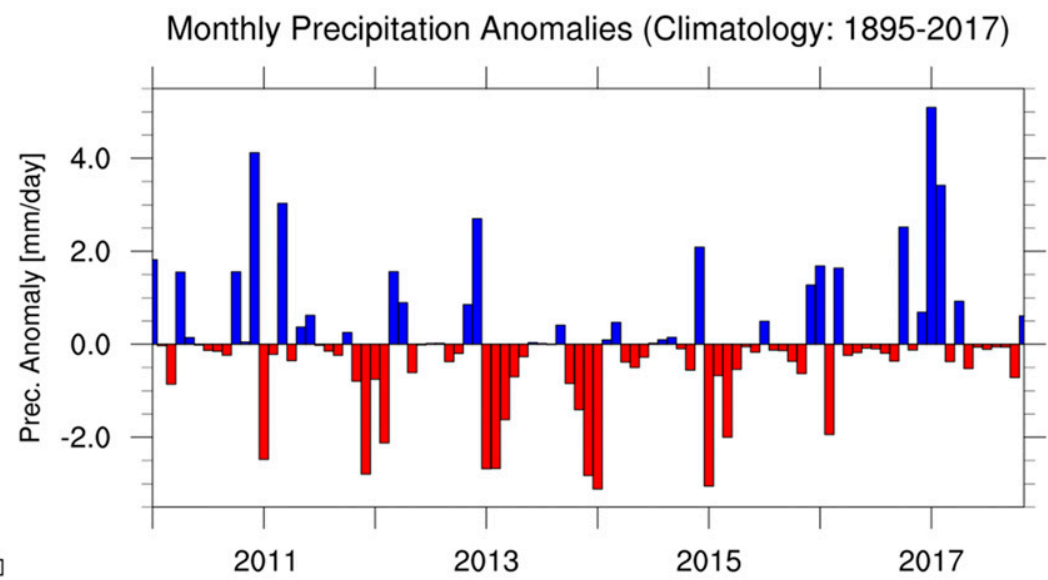

FIG. 1. (a) Spatial distribution of precipitation anomalies from October 2013 through March 2014. (b) Monthly time series of CA regional averaged precipitation anomalies from January 2010 through October 2017.

\section{b. Characteristics of meteorological drought}

The onset and recovery months of drought are detected by different threshold values of the SPI12, following the methods of Mo (2011). In her study, the SPI3 threshold values for onset and recovery are -0.8 and -0.2 , respectively. The threshold value for drought recovery is higher than that for drought onset to make sure that drought is fully recovered. In this study, the threshold values for the onset and recovery months of drought are -0.8 and 0.45 of the SPI12, respectively (red and blue dashed lines in Fig. 2b). We use a higher SPI12 value for drought recovery than the one used in Mo (2011) because the 2011-17 CA drought is treated as a single drought event in this study. The following characteristic statistics of the 2011-17 CA drought are computed: the month of drought onset, peak, and recovery (labeled A, B, and C in Fig. 2b, respectively), the duration of drought (the distance between $\mathrm{A}$ and $\mathrm{C}$ ), and the intensity of drought (B in Fig. 2b; the peak/minimum of the SPI12). Using our threshold values for drought onset and recovery, we detect the 23 other CA droughts with a duration longer than or equal to 3 months since 1895 . For the purpose of comparison, the 24 identified droughts were represented in the D-I curve.

\section{c. Data from Google Trends}

Google Trends is a public Internet facility of Google, Inc., that is based on Google Search, showing how popular a particular search term is over the specific time relative to the maximum volume of search activities given the chosen time (http://trends.google.com/trends). Google Trends provides the data of search interest at various spatial (global, national, state, metropolitan, and city levels) and temporal (monthly, weekly, and daily time step) scales. The well-known limitations of Google Trends data include 1) the limited temporal coverage (since 2004), 2) lack of detailed documentation for the generating algorithm (Nuti et al. 2014), and 3) noise from irrelevant events to the search term. Monthly time series of search interest have been used as indicators of public awareness in economics, environmental conservation, and water resources management (Choi and Varian 2012; Do et al. 2015; Gonzales and Ajami 2017). We downloaded monthly time series of the "all" search and "news" search activities within CA (2010-17) using the search term "drought". We retrieved the data several times on different dates to check the consistency; the results from the data retrieved on 21 June 2018 were represented in this study (Google 2018). We find that the key features (e.g., the timing of the peaks and the decay patterns after the peaks) of drought awareness are consistent among the retrieved Google Trends data while the actual magnitudes are slightly different but negligible. We also downloaded monthly time series of the "all" search activities within CA (2010-17) using the search term "flood" to understand interactions between drought and flood awareness, particularly the impact of the occurrences of floods on drought awareness during the stage of drought recovery.

The related topics and queries in Google Trends provide good information for potential noise topics. These noise topics are not relevant to the ongoing drought, but they are more related to the social events that occurred during the search period, 2010-17. For example, Beyonce's song "Love Drought" was released on 24 April 2016, which was not related to the ongoing drought in CA (noise). However, it is seen that the volume of the search activities using the search term "drought" was much 
(a) Standard Precipitation Index (3 months: PRISM)
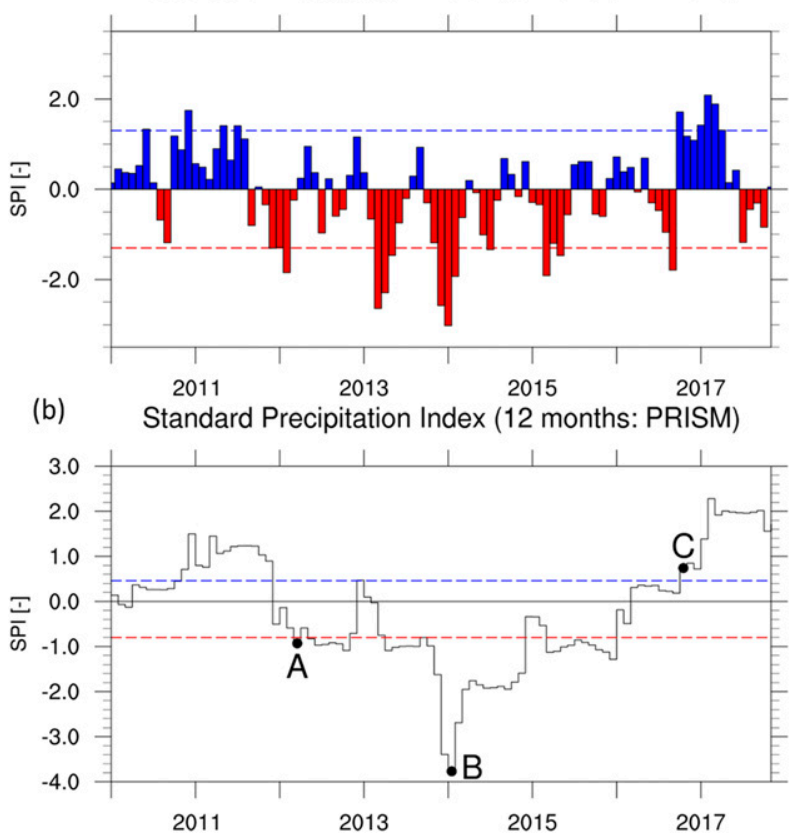

FIG. 2. (a) Monthly time series of 3-month SPI (SPI3) from January 2010 through October 2017. The dashed blue and red lines represent +1.6 and -1.6 of the SPI3 values, respectively, which thresholds indicate extreme climate (wet and dry) conditions. (b) Monthly time series of 12-month SPI from January 2010 through October 2017. Labels A, B, and C represent the month of initiation of drought, peak drought, and termination of drought, respectively. The dashed red and blue lines show the threshold values for drought onset $(-0.8)$ and recovery $(0.45)$, respectively.

higher than the volume of the search interest using the term "Love Drought" via the comparison function in Google Trends (see section S1 in the online supplemental material). This result means that the search activities of the interest group on the ongoing drought are much more active than that of the interest group on "Love Drought." In other words, the noise ("Love Drought") is much smaller than the signal (the peaks of drought awareness), which gives more reliability to using Google Trends for drought-awareness studies.

To explore whether the growth of available information about the ongoing drought elevates the public awareness on the actual drought risk, the trends of the quantity of available information about $\mathrm{CA}$ drought are collected and compared from Google Search, Google Scholar, and Web of Science. We find a slow growth of information quantity from Google Search, Google Scholar, and Web of Science (see section S2 in the supplemental material). This slow growth of available information is consistent to the growth of new media coverage during the 2011-17 CA drought (Quesnel and Ajami 2017). One of the potential causes is that there were more studies for the 2011-17 CA drought published after the drought recovery, indicating that the delayed data collection and publication processes affect the growth of available information. Interestingly, we find that the research topics are changed before and after drought recovery from mechanisms and predictability toward environmental and ecological impact assessments, indicating that it takes time to propagate meteorological drought to other types (agricultural, hydrological, and ecological) of drought and cause adverse effects on the environment.

In this study, we use Google Trends and Google Search to identify the potential triggers of the peaks of drought awareness (see section S3 in the supplemental material). A further study of the corresponding "true" triggers to the peaks of drought awareness is needed integrating online social monitoring data and other data sources (e.g., the online and offline survey data about drought awareness).

\section{d. A power-law decay model for drought awareness}

A power-law (PL) decay model has been used to describe the growth and decay patterns of social response to the social events through social networks. A recent study (Sano et al. 2013) found that a PL decay model captures the social dynamics better than an exponential model by validating their performances directly from the numbers of posting blogs involving a keyword. A more recent study (Fujiyama et al. 2016) proposed a PL decay model with autocorrelation that can capture growth and decay (asymmetric) patterns of social media activities using numbers of postings at Twitter before and after interest social events (predictable/scheduled). This study focuses on understanding only the decay patterns of drought awareness since the 2011-17 CA drought was not scheduled ("unpredictable" compared to social events; see Fujiyama et al. 2016). In general, natural disasterrelated (unpredictable) events grasp the public interest after the emergency. Here, we propose a PL decay model with autocorrelation for drought awareness. Monthly time series of search activities from the Google Trends data are used to fit a PL decay model [Eq. (1.2)]. The fitted PL parameter can characterize and compare the decay patterns of Californians' awareness of drought after the peak-related (natural/social) events. The expected value of drought awareness from the PL decay model with autocorrelation is written as

$$
\begin{aligned}
E\left(Y_{t} \mid Y_{t-1}\right) & =Y_{t-1} \frac{1}{\{[t-(t-1)]+1\}^{\alpha}} \quad(t \geq 1) \\
& =Y_{t-1} \frac{1}{2^{\alpha}}(t \geq 1),
\end{aligned}
$$

where $Y_{t}$ denotes the research interest from Google Trends at time $t$. For example, $Y_{0}$ is the value of the 
TABLE 1. Estimated parameters, magnitudes, minimum values, and potential triggers of the four peaks from the Google Trends data.

\begin{tabular}{lcccc}
\hline \hline & First peak & Second peak & Third peak & Fourth peak \\
\hline$\alpha$ & 0.66 & 0.48 & 0.21 & 0.91 \\
Peak value $\left(Y_{0, i}\right)$ & 51 & 53 & 78 & 100 \\
Minimum value $\left(Y_{\min , i}\right)$ & 17 & 18 & 16 & 8 \\
Potential triggers & $\begin{array}{c}\text { Peak of drought severity and } \\
\text { governor's declaration on } \\
\text { emergency }\end{array}$ & $\begin{array}{c}\text { Forecast on the strong El Niño } \\
\text { winter of 2014/15 }\end{array}$ & $\begin{array}{c}\text { Governors issue on } \\
\text { water use }\end{array}$ & $\begin{array}{c}\text { Floods in the } \\
\text { winter of 2017 }\end{array}$ \\
\hline
\end{tabular}

research interest index in the month with the occurrence of a peak $(t=0)$. The alpha parameter $\alpha$ is related to how rapidly an event (herein, a peak) loses interest after the event. A bigger value of $\alpha$ means that the event of a peak loses interest more quickly after the peak.

In this study, we focus on estimating the parameter and not on predicting the dynamics of drought awareness. Therefore, we treat each peak as an independent event and use the values of the peaks directly from the relative search activities in the months with the peak occurrences $\left[Y_{0, i} ; i\right.$ stands for the index of the corresponding peak event (from the first peak through the fourth peak)]. We estimate the parameters using the least squares method. Before estimating the parameters, we subtract the minimum values of interest search activities before the next peak $\left(Y_{\min , i}\right)$ (see Table 1$)$. After estimating the parameters, we add the minimum values into the simulated drought awareness. The error statistics show the fitted PL models succeed in describing both qualitatively and quantitatively the decay patterns of drought awareness after the four peaks.

\section{Results}

\section{a. Characteristics of the historical CA droughts}

The 24 historical CA droughts since 1895 are characterized in the D-I curve (Fig. 3). The average of the return periods of the identified drought is five years. The 2011-17 CA drought is the first drought in terms of intensity $(-3.8)$ and the third drought in terms of duration (53 months). The two well-known drought decades for CA are detected, the 1920s-1930s and 1970s-1980s. The first drought decade since 1895 is detected by the two drought events over 1923-27 and 1928-35 (Mirchi et al. 2013). The 1923-27 CA drought started in March 1923 and terminated in January 1927 with a duration of 47 months and intensity of -2.6 (SPI12). After a short relief period (10 months), the longest drought since 1895 started in November 1928 and continued over the next $6.5 \mathrm{yr}$ (March 1935).

The next major drought decades were detected by the two major droughts over 1975-78 and 1987-94. The 1975-78 drought was initiated in January 1975 and terminated in February 1978. It has a duration of 38 months and an intensity of -2.55 (the third ranked). The 1987-94 drought began in February 1987 and ended in January 1993 with a duration of 72 months and an intensity of -2.51 (the fourth ranked). Between two major drought events, there were two short-term droughts (the 1981 and 1985-86 droughts).

The rest of the identified droughts include nine shortterm $(<1 \mathrm{yr})$ droughts and five multiyear droughts ( 3 and $4 \mathrm{yr}$ ). The relationship between duration and intensity of the identified CA droughts showed a statistically significant anticorrelation at the rate of -0.27 of SPI12 per year, which means that the droughts with lower intensity (more severe) persist longer. The 2011-17 CA drought was an outlier of this relationship because of its strongerthan-expected intensity $(-3.8$; the estimated intensity is -2.26 given the drought duration of 53 months). The intensity of the most recent CA drought is of particular

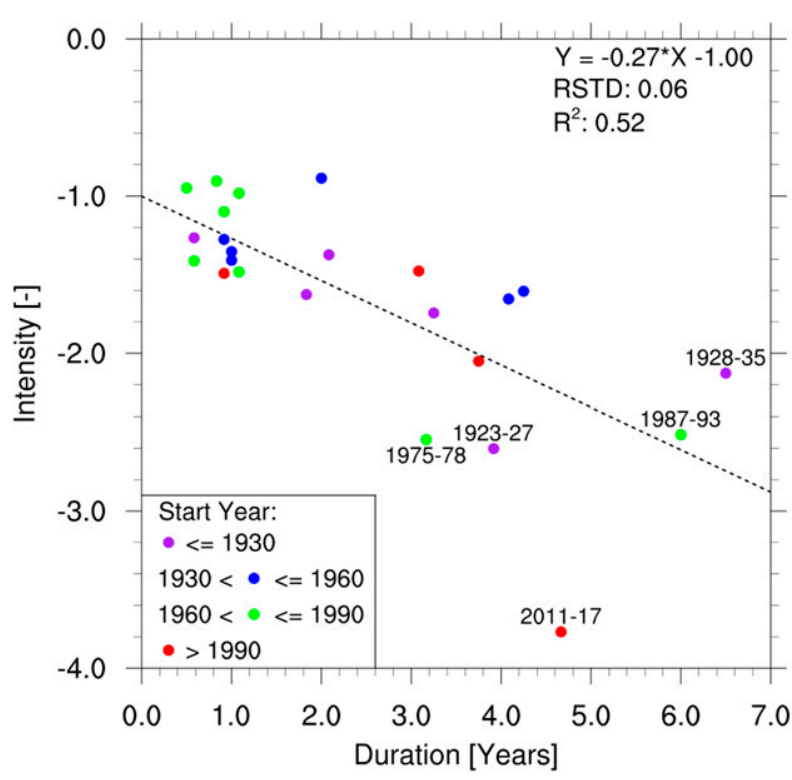

FIG. 3. D-I curve of the 24 major CA droughts over 1895-2017. The worst five major droughts are labeled with the start and end year. The regression coefficient and $y$ intercept are represented in the top-right corner. RSTD and $R^{2}$ stand for standard error of the regression coefficient and the coefficient of determination, respectively. 
interest because it may have resulted in increased saliency of the drought to the public, a factor that has been suggested to influence critical awareness of hazardous events (Paton 2003). This unprecedented intensity of the 201117 CA drought will provide us a unique opportunity to explore the social response of CA residents by reducing the relative magnitude of noise search activities associated with the irrelevant social events in the community to the ongoing drought.

\section{b. Potential triggers of the peaks of drought awareness}

Figure 4 shows monthly time series of relative search activities for the term "drought" through "all" search (Fig. 4a) and "news" search (Fig. 4b). The first peak of drought awareness is in January 2014 (label A in Fig. 4a). The drought severity reaches a peak ( -3.8 of SPI12) during that month. There is a 2-yr gap from the drought onset month (March 2012) to the first spike of drought awareness (January 2014). The potential causes of such a big gap include the intrinsic creeping phenomenon and the 2012 Midwestern drought. This peak of drought awareness coincides with both the intensity of drought and the governor's declaration. The next peak of drought awareness occurred in August 2014 (label B) when the seasonal forecasts of a strong El Niño winter in 2014/15 became less certain. In general, CA has more precipitation than normal during a strong El Niño winter; however, it had less precipitation than expected during the strong El Niño winter in 2014/15. It was reported as a fragile relationship between El Niño and CA precipitation (Lee et al. 2018), which led to the second peak of relative search interest activities over CA during the 2014/15 winter (see section S4 in the supplemental material). Another potential trigger of the second peak was related to the mandatory outdoor water conservation regulation in CA (Gonzales and Ajami 2017). This mandatory regulation was released on 15 July 2014 and went into effect around 1 August 2014 to reduce Californians' water use by $20 \%$.

The third peak of drought awareness happened in April 2015 (label C) when the CA governor issued water rules (1 April 2015). The statewide goal of the water use rule was to collectively reduce water use by $25 \%$ (with respect to 2013), but the restrictions and specific targets were not the same across the board. The SPI12 value however improved slightly after the month with the drought intensity (the minimum of the SPI12 value; January 2014). It suggests that the governor's issue for water rules plays a role in triggering the peak of drought awareness in April 2015.

The last peak of drought awareness occurred in January 2017 (label D) before the governor's declaration of drought recovery (7 April 2017). According to Google (a) Search Interest for Drought in California (All Search)

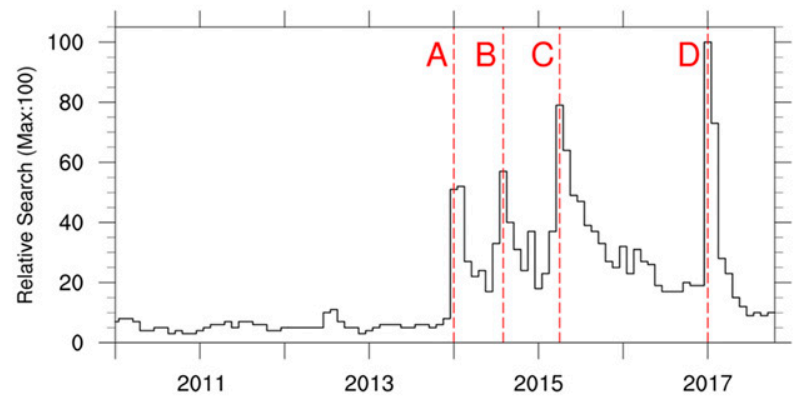

(b) Search Interest for Drought in California (News Search)

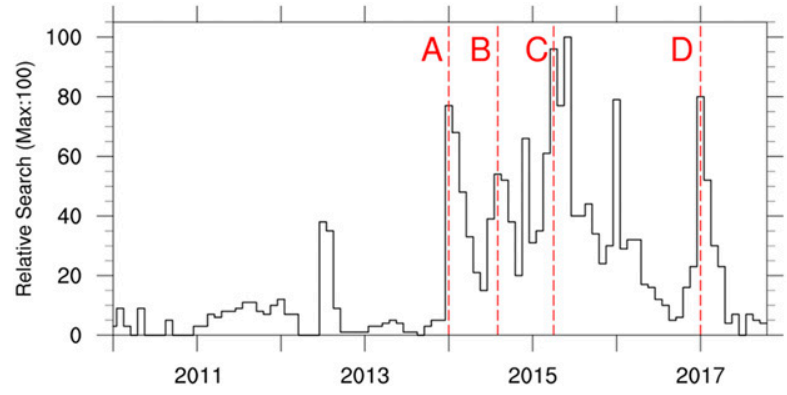

FIG. 4. Monthly time series of (a) all search interest and (b) news search interest using the term "drought" from Google Trends. Vertical red dashed lines represent the month when the governor declared drought emergency (January 2014; label A), the month when the forecast of a strong El Niño winter was available (August 2014; B), the month when the governor issued a water rule (April 2015; C), and the month when the flood occurred (January 2017; D).

Trends, the rising topics were flood, Lake Mead, and the Oroville dam during the drought recovery period (January 2015-October 2017). The rising queries are related to drought persistence and recovery and Oroville dam (e.g., "Is California still in drought?"). It suggests that the occurrence of floods related to drought recovery (e.g., CA floods in early 2017) influences drought awareness and serves as a potential trigger of the peak of drought awareness, particularly during the stage of drought recovery. In the next section, we present an analysis of interactions between drought and flood awareness at the daily time step because flood is a much quicker event, which makes it different to see the dynamic patterns of flood awareness at the monthly time step.

\section{c. Interactions of drought awareness and flood awareness}

To investigate the interactions of drought and flood awareness, daily times series of relative search interest for "drought" and "flood" from Google Trends are shown in Fig. 5 (red and blue line, respectively). Within CA, flood awareness is at a certain level (around 20 relative search interest) before the floods in early 2017, whereas 
(a) Comparison of Search Interest in CA: Drought vs Flood

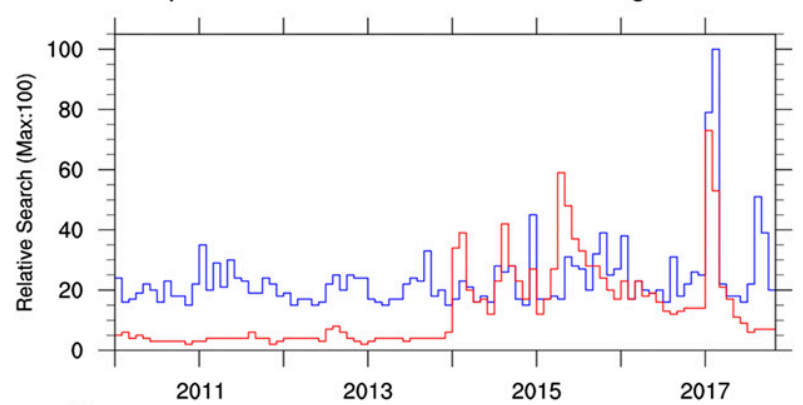

(b) Search Interest for Drought in CA (December 2016 to April 2017)

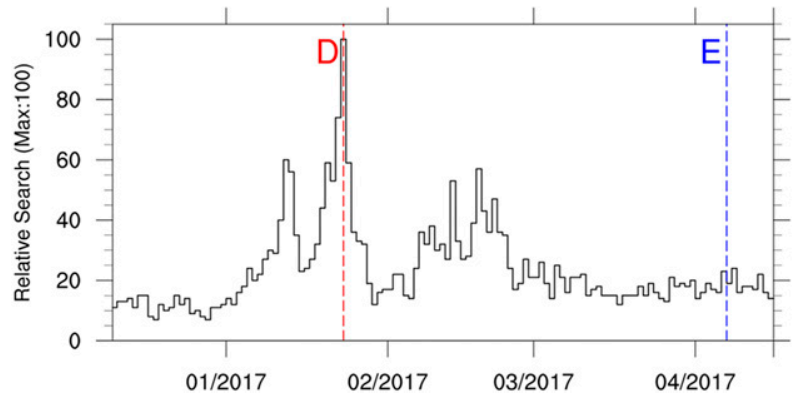

FIG. 5. (a) Daily time series of relative search interest for the terms "drought" and "flood" (red and blue lines, respectively) within CA from Google Trends. (b) Daily time series of relative search interest for the term "drought" from December 2016 through April 2017. Labels D and E represent the date on which the governor declared the state of emergency after storms caused floods and landslides and the date on which the governor declared drought recovery, respectively.

drought awareness is relatively much lower (around 5) before its first peak. It indicates that Californians have a tendency to have stronger social memory/higher awareness in flood situations and, as a result, respond quickly to flood. It is further supported by the maximum level of drought awareness during the drought recovery stage when the risk of pluvial was rapidly increased relative to previous peaks. A cluster of positive SPI3 above +1.6 from late 2016 and early 2017 (Fig. 2a) is a good indicator of a signal of drought recovery from SPI12 (Fig. 2b). It suggests that using the multitime window of the SPIs can characterize the risk of flood and drought better, particularly during an abrupt droughtto-flood transition. We find that 7 of the remaining 23 identified CA meteorological droughts are suddenly terminated by floods, as in the 2011-17 CA drought recovery. Here, a rapid drought recovery is defined and detected as the recovery month has a sudden increase of SPI12 (a positive SPI12 value) from the previous month (a negative SPI value) by 2 or greater. Historically, $33 \%-40 \%$ of the historical CA drought recoveries since 1885 have been brought about by landfalling atmospheric-river (AR) storms (Dettinger 2013). The results highlight that we need to develop an effective drought recovery warning message, particularly when we face AR storm landfalls during the drought recovery stage, to adapt easily the sudden changes in water resources management for flood mitigation and thus to increase the resilience of our community against AR-driven floods.

During the drought recovery stage, a high level of drought awareness of the stakeholders and the public and their recent experience make them keep the water resources management and policy for drought mitigation even when reliable forecasts for coming floods are available, raising a question as to whether the incoming storm will bring enough rainfall for drought recovery. However, a reliable flood forecast itself increases flood awareness rapidly. When the community has a high level of drought awareness at the same time, it will take more time for the local stakeholders and the public to make decisions. In other words, they may have a higher chance of missing the "golden" time for mitigation of the coming floods, amplifying the adverse effect of the floods. A good example is the Oroville Dam crisis in February 2017.

The current sociohydrological modeling for flood and drought (Di Baldassarre et al. 2013, 2017; van Emmerik et al. 2014; Yu et al. 2017) considers only the status and risk of the interest disaster itself in modeling social memory/awareness. It does not take into account the level of social memory/awareness of other types of disasters as a potential trigger of awareness of the interest disaster (herein drought). The findings of this study suggest that there is a need to develop a social dynamic model for drought awareness that can take into account interactions with the level of public awareness of other types of disasters (herein flood) as a trigger of the peak of the interest disaster awareness raising a question whether it is recovered or continues. This will help local stakeholders and the public in "real" communities to adjust drought and flood awareness in a timely manner.

\section{d. Decay patterns of drought awareness}

Figure 6 shows monthly time series of drought awareness (search interest) from the Google Trends data (blue line) and the fitted PL decay model with different parameters during the periods after the four peaks. We estimate the $\alpha$ of the PL model for the four peaks using the Google Trends data (Table 1). The fitted PL model indicates that people lost their interest in drought quickly after the first peak related to the co-occurrence of the peak of drought severity and the governor's declaration on emergency (the second highest $\alpha$ ). People lost their interest in drought slowly after the second peak related to the $2015 \mathrm{El} \mathrm{Niño} \mathrm{forecast} \mathrm{and/or} \mathrm{outdoor} \mathrm{water} \mathrm{use}$ 
(a) $1^{\text {st }}$ Peak (1/2014 - 6/2014)

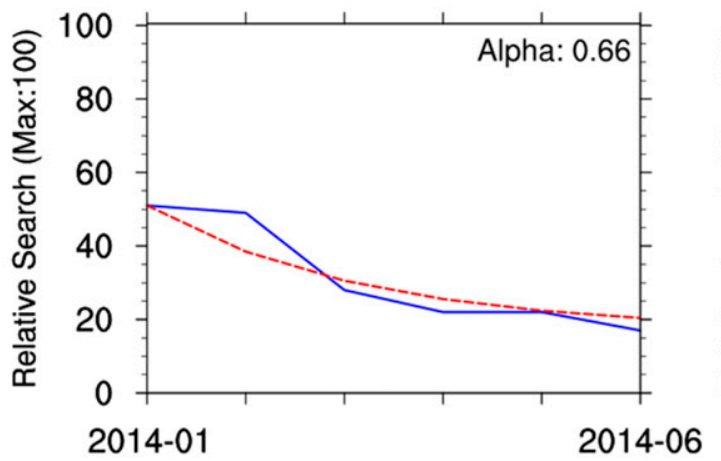

(b) $2^{\text {nd }}$ Peak $(8 / 2014-3 / 2015)$

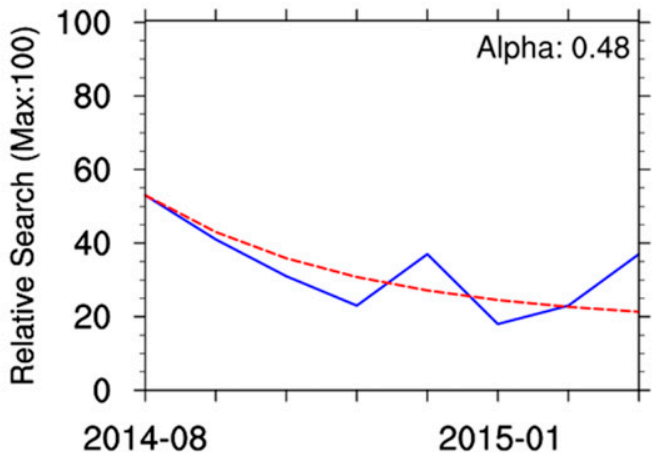

(c) $3^{\text {rd }}$ Peak $(4 / 2015-12 / 2016)$

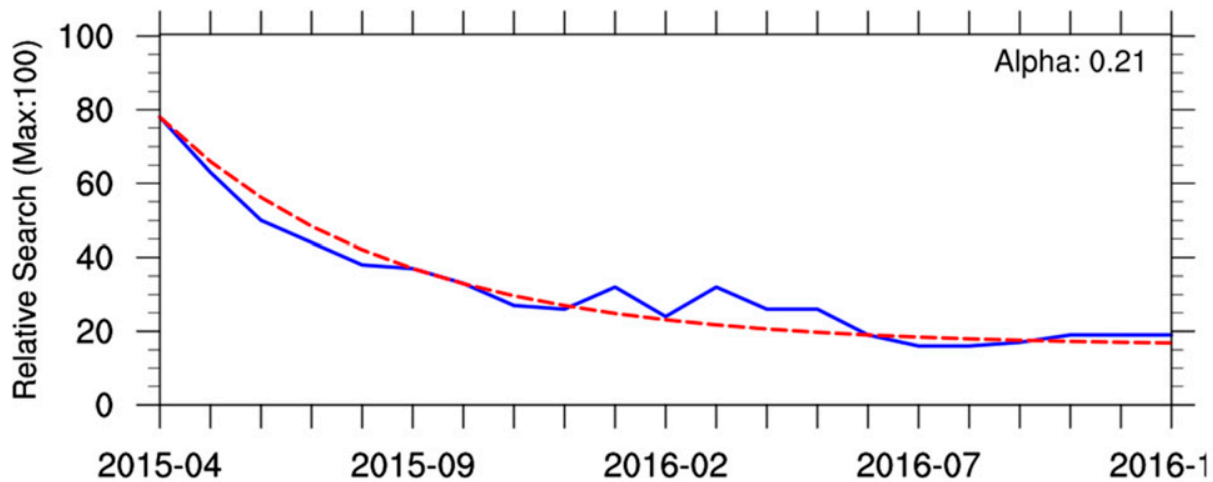

(d) $4^{\text {th }}$ Peak $(1 / 2017-12 / 2017)$

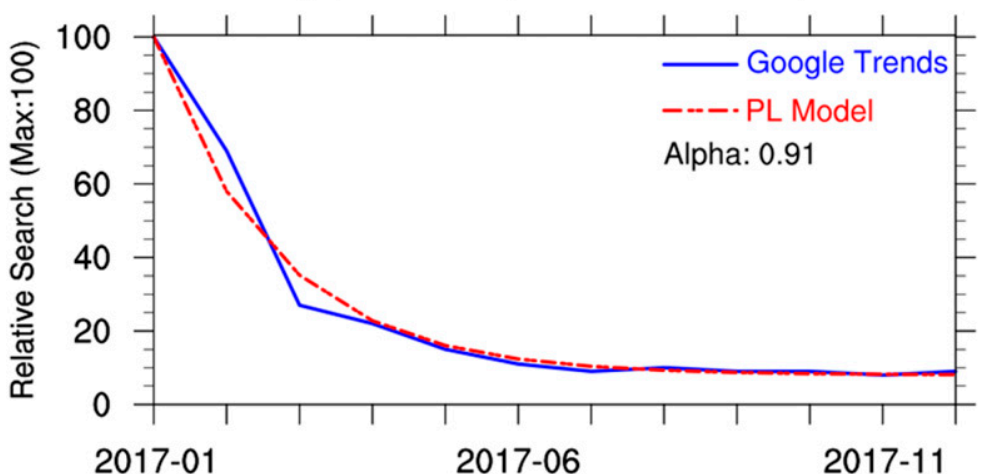

FIG. 6. Monthly time series of research interest in drought (herein, drought awareness) during the periods after the peaks from Google Trends data (blue solid line) and the fitted PL decay model (red dashed line). The values of the alpha parameters of the PL decay model (label Alpha) for the four peaks are given in the top-right corners of (a)-(d).

regulation (the second lowest $\alpha$ ). After the third peak related to the governor's water use issue, people remained interested in drought longer than any other peaks (the lowest $\alpha$ ). After the last peak related to the occurrences of floods in early 2017, people lost their interest in drought most quickly (the highest $\alpha$ ). The results from the fitted PL decay model indicate that Californians lost their interest in drought more quickly by a factor of 2 after the natural factor-related events (the average of the $\alpha \mathrm{s}$ is 0.79 ) than they did after the social factor-related peaks
(0.35). It suggests that better scheduling of the water use regulation rule release (e.g., the announcement of the water use regulation in advance) might improve the level of drought awareness and thus lead to public support for it when it is released.

\section{Conclusions}

This study succeeds in understanding the potential triggers and dynamics of drought awareness during the 
2011-17 California drought using Google Trends data. The key findings of this study are that 1 ) there was no detectable social response during the onset of the 201117 CA drought, 2) the potential triggers of the peaks of drought awareness include both human (governor's actions and the forecasts) and natural (the peak of drought severity and the occurrence of flood) factors, and 3) Google Trends data can be used to develop a stochastic model for drought awareness (herein, a PL decay model) that can describe and characterize the realistic decay patterns of drought awareness after the peaks.

This study is a case study on social dynamics during the onset, persistence, and recovery of a recent CA drought event. The findings of this study indicate that Google Trends can be utilized in understanding and modeling human-drought interactions in real communities. The identified "potential" triggers and dynamic patterns from this study may be different from other drought events because of the different characteristics (severity, duration, and intensity) of the drought and different societal structure of the affected communities. Thus, case studies for other historical droughts in CA and other places will be necessary to corroborate this information. Also, data from Google Trends are sensitive to technology development, socioeconomic interests, and education due to the data collection method. To overcome the limited temporal coverage of web-search data, historical social datasets from traditional surveys and interviews can be facilitated to reconstruct historical drought awareness (before 2004) through comparison and cross-validation studies with traditional data and web-based social data over the common period (since 2004).

The impacts of climate change on AR-related storms and their role in recovering the future CA droughts are unclear. California needs to prepare an effective warning system during sudden drought-to-flood transitions driven from landfalling AR storms. Improvement of both the AR forecasting skill and risk communication with Californians is crucial to elevate the community resilience against AR-driven floods, particularly during the stage of drought recovery.

The current barriers of the sociohydrological modeling include a lack of studies of drought awareness using social monitoring data, a simple representation of drought awareness in the coupled human-natural system modeling, and missing calibration in sociohydrological modeling for real communities. This study gives us new insight into how these current barriers can be tackled using Google Trends data and other social monitoring data. A sociohydrological model calibrated and/or validated social monitoring data, such as Google Trends, will become a key tool to describe and predict social response of real communities during the emergence of drought, which can provide timely strategies for drought preparedness and recovery.

Acknowledgments. We thank the PRISM Climate Group and Google Trends for making available the climate and Internet search data, respectively. This work was made possible in part by the UCAR-funded project SUBAWD000837 and a grant of high-performance computing resources and technical support from the Alabama Supercomputer Authority. This study is also partially supported by the University of Alabama Graduate Council Fellowship (for Sungyoon Kim).

\section{REFERENCES}

Aerts, J. C. J. H., and Coauthors, 2018: Integrating human behaviour dynamics into flood disaster risk assessment. Nat. Climate Change, 8, 193-199, https://doi.org/10.1038/s41558-018-0085-1.

Bartlett, F. C., 1932: Remembering: A Study in Experimental and Social Psychology. Cambridge University Press, 327 pp.

Buluç, L., C. Fischer, J. Ko, J. Balachowski, and S. Ostoja, 2017: Drought and tree mortality in the Pacific Southwest region. USDA Forest Service Fact Sheet, 14 pp., https://www.fs.fed.us/ psw/topics/tree_mortality/california/documents/DroughtFactSheet_ R5_2017.pdf.

Choi, H., and H. Varian, 2012: Predicting the present with Google Trends. Econ. Rec., 88 (S1), 2-9, https://doi.org/10.1111/j.14754932.2012.00809.x.

Christian-Smith, J., M. C. Levy, and P. H. Gleick, 2015: Maladaptation to drought: A case report from California, USA. Sustain. Sci., 10, 491-501, https://doi.org/10.1007/s11625-014-0269-1.

Daly, C., M. Halbleib, J. I. Smith, W. P. Gibson, M. K. Doggett, G. H. Taylor, J. Curtis, and P. Pasteris, 2008: Physiographically sensitive mapping of climatological temperature and precipitation across the conterminous United States. Int. J. Climatol., 28, 2031-2064, https://doi.org/10.1002/joc.1688.

Dettinger, M. D., 2013: Atmospheric rivers as drought busters on the U.S. West Coast. J. Hydrometeor., 14, 1721-1732, https:// doi.org/10.1175/JHM-D-13-02.1.

Di Baldassarre, G., A. Viglione, G. Carr, L. Kuil, J. L. Salinas, and G. Blöschl, 2013: Socio-hydrology: Conceptualising humanflood interactions. Hydrol. Earth Syst. Sci., 17, 3295-3303, https://doi.org/10.5194/hess-17-3295-2013.

_, F. Martinez, Z. Kalantari, and A. Viglione, 2017: Drought and flood in the Anthropocene: Feedback mechanisms in reservoir operation. Earth Syst. Dyn., 8, 225-233, https://doi.org/10.5194/ esd-8-225-2017.

Do, Y., J. Y. Kim, M. Lineman, D. Kim, and G. Joo, 2015: Using internet search behavior to assess public awareness of protected wetlands. Conserv. Biol., 29, 271-279, https:// doi.org/10.1111/cobi.12419.

Dunbar, P. K., 2007: Increasing public awareness of natural hazards via the Internet. Nat. Hazards, 42, 529-536, https://doi.org/ 10.1007/s11069-006-9072-3.

Fujiyama, T., C. Matsui, and A. Takemura, 2016: A power-law growth and decay model with autocorrelation for posting data to social networking services. PLOS ONE, 11, e0160592, https://doi.org/10.1371/journal.pone.0160592.

Gonzales, P., and N. Ajami, 2017: Social and structural patterns of drought-related water conservation and rebound. Water 
Resour. Res., 53, $10619-10634$, https://doi.org/10.1002/ 2017WR021852.

Google, 2018: The relative search activity index from Google Trends. Google, accessed 21 June 2018, https://trends.google.com/ trends/.

Howitt, R., J. Medellín-Azuara, D. MacEwan, J. R. Lund, and D. Sumner, 2014: Economic analysis of the 2014 drought for California agriculture. University of California, Davis, Center for Watershed Sciences Rep., 28 pp., https:/watershed.ucdavis.edu/ files/biblio/DroughtReport_23July2014_0.pdf.

, D. MacEwan, J. Medellín-Azuara, J. Lund, and D. Sumner, 2015: Economic analysis of the 2015 drought for California agriculture. University of California, Davis, Center for Watershed Sciences Rep., 17 pp., https://watershed.ucdavis. edu/files/biblio/Economic_Analysis_2015_California_Drought_ Main_Report.pdf.

Lee, S., H. Lopez, E. Chung, P. DiNezio, S. Yeh, and A. T. Wittenberg, 2018: On the fragile relationship between El Niño and California rainfall. Geophys. Res. Lett., 45, 907-915, https://doi.org/10.1002/2017GL076197.

McKee, T. B., N. J. Doesken, and J. Kliest, 1993: The relationship of drought frequency and duration to time scales. Proc. Eighth Conf. of Applied Climatology, Anaheim, CA, Amer. Meteor. Soc., 179-184.

Medellín-Azuara, J., D. MacEwan, R. E. Howitt, D. A. Sumner, and J. R. Lund, 2016: Economic analysis of the 2016 California drought on agriculture. University of California, Davis, Center for Watershed Sciences Rep., 17 pp., https://watershed.ucdavis.edu/ files/DroughtReport_20160812.pdf.

Mirchi, A., K. Madani, M. Roos, and D. W. Watkins, 2013: Climate change impacts on California's water resources. Drought in Arid and Semi-Arid Regions: A Multi-Disciplinary and CrossCountry Perspective, K. Schwabe et al., Eds., Springer, 301-319.

Mo, K. C., 2011: Drought onset and recovery over the United States. J. Geophys. Res., 116, D20106, https://doi.org/10.1029/ 2011JD016168.

Mostert, E., 2018: An alternative approach for socio-hydrology: Case study research. Hydrol. Earth Syst. Sci., 22, 317-329, https://doi.org/10.5194/hess-22-317-2018.

Murdock, V., 2011: Your mileage may vary: On the limits of social media. SIGSPATIAL Special, 3 (2), 62-66, https://doi.org/ 10.1145/2047296.2047309.

Musaev, A., K. Stowers, and J. Kam, 2018: Harnessing data to create an effective drought management system. 15th Int. Conf. on Information Systems for Crisis Response and Management (ISCRAM), Rochester, NY, ISCRAM Association, 544-552.

Neisser, U., and N. Harsch, 1992: Phantom flashbulbs: False recollections of hearing the news about Challenger. Emory Symposia in Cognition 4: Affect and Accuracy in Recall: Studies of "Flashbulb" Memories, E. Winograd and U. Neisser, Eds., Cambridge University Press, 9-31.

Niles, M. T., M. Lubell, and V. R. Haden, 2013: Perceptions and responses to climate policy risks among California farmers. Global Environ. Change, 23, 1752-1760, https://doi.org/10.1016/ j.gloenvcha.2013.08.005.

Nuti, S. V., B. Wayda, I. Ranasinghe, S. Wang, R. P. Dreyer, S. I. Chen, and K. Murugiah, 2014: The use of Google Trends in health care research: A systematic review. PLOS ONE, 9, e109583, https://doi.org/10.1371/journal.pone.0109583.
Paton, D., 2003: Disaster preparedness: A social-cognitive perspective. Disaster Prev. Manage., 12, 210-216, https://doi.org/ 10.1108/09653560310480686.

Quesnel, K. J., and N. K. Ajami, 2017: Changes in water consumption linked to heavy news media coverage of extreme climatic events. Sci. Adv., 3, e1700784, https://doi.org/10.1126/sciadv.1700784.

Sampei, Y., and M. Aoyagi-Usui, 2009: Mass-media coverage, its influence on public awareness of climate-change issues, and implications for Japan's national campaign to reduce greenhouse gas emissions. Global Environ. Change, 19, 203-212, https://doi.org/10.1016/j.gloenvcha.2008.10.005.

Sano, Y., K. Yamada, H. Watanabe, H. Takayasu, and M. Takayasu, 2013: Empirical analysis of collective human behavior for extraordinary events in the blogosphere. Phys. Rev. E, 87, 012805, https://doi.org/10.1103/PhysRevE.87.012805.

Seifter, A., A. Schwarzwalder, K. Geis, and J. Aucott, 2010: The utility of "Google Trends" for epidemiological research: Lyme disease as an example. Geospat. Health, 4, 135-137, https://doi.org/ 10.4081/gh.2010.195.

Sen, P. K., 1968: Estimates of the regression coefficient based on Kendall's tau. J. Amer. Stat. Assoc., 63, 1379-1389, https://doi.org/ 10.1080/01621459.1968.10480934.

Sivapalan, M., H. H. G. Savenije, and G. Blöschl, 2012: Sociohydrology: A new science of people and water. Hydrol. Processes, 26, 1270-1276, https://doi.org/10.1002/hyp.8426.

Switzer, D., and A. Vedlitz, 2017: Investigating the determinants and effects of local drought awareness. Wea. Climate Soc., 9, 641-657, https://doi.org/10.1175/WCAS-D-16-0052.1.

Tang, Z., L. Zhang, F. Xu, and H. Vo, 2015: Examining the role of social media in California's drought risk management in 2014. Nat. Hazards, 79, 171-193, https://doi.org/10.1007/s11069-015-1835-2.

Troy, T. J., M. Pavao-Zuckerman, and T. P. Evans, 2015: Debates-Perspectives on socio-hydrology: Socio-hydrologic modeling: Tradeoffs, hypothesis testing, and validation. Water Resour. Res., 51, 4806-4814, https://doi.org/10.1002/ 2015WR017046.

van Emmerik, T. H. M., Z. Li, M. Sivapalan, S. Pande, J. Kandasamy, H. H. G. Savenije, A. Chanan, and S. Vigneswaran, 2014: Sociohydrologic modeling to understand and mediate the competition for water between agriculture development and environmental health: Murrumbidgee River basin, Australia. Hydrol. Earth Syst. Sci., 18, 4239-4259, https://doi.org/10.5194/hess-18-4239-2014.

Viglione, A., G. Di Baldassarre, L. Brandimarte, L. Kuil, G. Carr, J. L. Salinas, A. Scolobig, and G. Blöschl, 2014: Insights from socio-hydrology modelling on dealing with flood risk-Roles of collective memory, risk-taking attitude and trust. J. Hydrol., 518, 71-82, https://doi.org/ 10.1016/j.jhydrol.2014.01.018.

Vosen, S., and T. Schmidt, 2011: Forecasting private consumption: Survey-based indicators vs. Google trends. J. Forecast., 30, 565-578, https://doi.org/10.1002/for.1213.

$\mathrm{Xu}$, L., P. Gober, H. S. Wheater, and Y. Kajikawa, 2018: Reframing socio-hydrological research to include a social science perspective. J. Hydrol., 563, 76-83, https://doi.org/ 10.1016/j.jhydrol.2018.05.061.

Yu, D. J., N. Sangwan, K. Sung, X. Chen, and V. Merwade, 2017: Incorporating institutions and collective action into a sociohydrological model of flood resilience. Water Resour. Res., 53, 1336-1353, https://doi.org/10.1002/2016WR019746. 